J. Dairy Sci. 96:5027-5034

http://dx.doi.org/10.3168/jds.2012-6276

(c) American Dairy Science Association ${ }^{\circledR}, 2013$.

\title{
Hazard perception of Dutch farmers and veterinarians related to dairy young stock rearing
}

\author{
J. S. C. Boersema, ${ }^{* 1,2}$ J. P. T. M. Noordhuizen ${ }^{*} \dagger$ and J. J. Lievaart ${ }^{*}$ \\ ${ }^{*}$ School of Animal and Veterinary Sciences, Charles Sturt University, Wagga Wagga 2795, Australia \\ †VACQA-International Consultancy, 2005-110 Santarém, Portugal
}

\section{ABSTRACT}

A group of 110 dairy farmers and 26 bovine veterinarians participated in a web-based questionnaire using the adaptive conjoint analysis technique to rank their perception regarding several hazards during 6 subsequent periods of the process of dairy young stock rearing. The method applied only involved selected respondents with a high consistency in their answering (correlation $>30 \%$ ). For the ranking, answers were first transformed into a utility score (US) for each hazard. The final ranking for each of the 6 periods was based on the US per hazard separately for farmers and veterinarians. Besides the ranking, the absolute values and the US itself were also compared between farmers and veterinarians to determine any statistically significant differences between the levels of the score despite the ranking. The overall conclusion is that, for almost every designated period, the ranking of the hazards differed between farmers and veterinarians. Only 1 period was observed (period IV, Pregnancy period until 4 weeks before calving) where veterinarians and farmers had the same top 3 ranking of the hazards, namely "Mastitis," "Abortion," and "Poor growth rate of the pregnant heifer." Major differences between farmers and veterinarians were seen during period II (feeding milk until weaning) for the hazard "Diarrhea in older calf," which was considered less important by farmers compared to veterinarians, and period number III (weaning until insemination) for "Over-condition," which, again, was seen as the most important hazard by veterinarians, but only ranked as number 5 by farmers. Besides the ranking, significant differences in absolute US values between veterinarians and farmers were seen in "Infection with Johne's disease" (14.5 vs. 7.8), "Diarrhea in newborn calf" (18.2 vs. 12.2), and "Insufficient feed intake" (16.2 vs. 8.4) in period I (colostrum until transition to milk replacer). Lameness represented the most

Received October 17, 2012

Accepted April 18, 2013.

${ }^{1}$ Corresponding author: sboersema@vanstadtotwad.nl

${ }^{2}$ Current address: Boterdiep WZ 49, 9781 EL Bedum, the Netherlands. important significant difference in absolute values in period III (weaning until insemination; 6.3 vs. 14.3), which was again significant in period $\mathrm{V}$ (4 wks before calving until calving; 7.4 vs. 12.1). The outcome of this study shows that hazard perception of veterinarians and farmers differs for most rearing periods (in ranking and absolute values). The outcome of this study can be used for 2 purposes: first, to improve communication between farmers and their consulting veterinarian about hazards and hazard perception in young stock rearing; and second, the US scores can be used to select top priority hazards which should at least be integrated into management advisory programs to improve dairy young stock rearing.

Key words: young stock rearing, hazard perception, adaptive conjoint analysis, the Netherlands

\section{INTRODUCTION}

Throughout the world, rearing replacement heifers is one of the largest investments on dairy farms; therefore, this process has been extensively examined for optimization (Cady and Smith, 1996; Mourits et al., 1997). For example, in the Netherlands, approximately $30 \%$ of dairy cattle are culled each year (CRV, 2009) compared with 25\% in Scotland (Bell et al., 2010) and 30 to 40\%, on average, in the United States (Hadley et al., 2006). Still, veterinarians and nutritionists often note that several farmers, rearing their own replacement heifers, somehow neglect the importance of this process as an essential part of the whole farm management system. Many are not aware of the effect of common hazards (e.g., diseases such as diarrhea and pneumonia) that result in animals less suitable to replace culled cows and an increased investment per raised heifer (Mourits et al., 1997). In a Dutch study, estimated rearing costs varied between €1,423 and 1,715 per animal depending on growth rate and disease uncertainty (Mohd Nor et al., 2012).

Currently, between 55 and $70 \%$ of Dutch dairy farmers (Lievaart et al., 2008; Derks et al., 2012) implement, on a voluntary basis, the on-farm veterinary Herd Health and Production Management advisory service (HHPM) to support their daily farm management. 
A core element in these programs, which can include young stock rearing, is to identify and rank important on-farm hazards. Until now, the uptake of monitoring and controlling young stock rearing via HHPM programs has been low because farmers may be unaware of the costs and veterinarians fail to show farmers the economic benefits (Lievaart et al., 2008; Derks et al., 2012). A possible solution to increase awareness regarding hazards and deal with the uncertainty in the process of young stock rearing would be the systematic identification of major hazards and implementation of monitoring protocols in the rearing process (Boersema et al., 2008).

This more structured and formal approach of hazard and risk management is in line with General Food Law EC178-2002 and Directives EC 852-853-854/2004 in the European Union (http://eur-lex.europa.eu). These guidelines state that, at each level in the dairy food chain, stakeholders should use Hazard Analysis and Critical Control Points (HACCP) quality management programs to assure food product safety (Evans and Lindsay, 1996; FAO, 1997). Until now, dairy farms, being the basic element in the dairy food chain, did not implement such a program-nor did they need to. The dairy farm production system is comparable to other companies in the food chain and consists of several (production) steps with hazards, risks, and critical control points. Replacement rearing is a core part of the dairy farm process, well suitable to apply a HACCPlike quality risk management (QRM) program; these programs could be the next step to upgrade, improve, or replace current HHPM programs.

This study used the adaptive conjoint analysis (ACA) technique to rank hazards in young stock rearing in the Dutch dairy sector by interviewing both dairy farmers and bovine veterinarians. The ACA technique converts the preferences of respondents into quantitative utility score (US) and simultaneously tests the consistency in the farmers' and veterinarians' answers. The objective of this study was to rank the hazard perception of veterinarians and farmers to obtain a short list of hazards for various stages of the young stock rearing process. In the future, the outcome of this study can be used to improve communication between veterinarians and farmers and to upgrade the current HHPM programs to QRM programs, thereby improving monitoring and controlling on-farm risks in young stock rearing.

\section{MATERIALS AND METHODS}

\section{Participants}

In total, 45 bovine veterinarians from 12 veterinary practices throughout the Netherlands were asked by telephone to participate in a web-based ACA questionnaire. Practitioners were selected based on the HHPM programs they provided to a substantial part of their clients' dairy farms on a regular basis and frequently collaborated with Utrecht University (Utrecht, the Netherlands) for various research projects. Participating veterinarians were sent a conformation by email. Farmers were selected randomly via their veterinarians within 1 wk after the first contact with the veterinarian.

Both groups were asked the same questions regarding hazards in young stock rearing, but some additional background questions differed between veterinarians and farmers. Therefore, 2 separate surveys were developed: one called "VET" for veterinarians and a second called "FARM" for dairy farmers. All respondents received an access code for the online questionnaire with a cover letter explaining the purpose of the questionnaire by mail within 2 wk after first contact. Respondents had 8 wk to complete the questionnaire, and, 1 wk before closure, all veterinary practices and farmers received a reminder by email to participate in the survey. This technique has been applied in other dairy production-related studies before (Valeeva et al., 2005; Lievaart and Noordhuizen, 2011)

\section{ACA and Questionnaire Design}

An ACA is an interview technique that is used in marketing investigations to determine the preferences of consumers for a certain product. In a conjoint analysis, personal preferences regarding certain components (attributes) of a product or an event are examined and a quantitative US is created from the result. Each component has several choices (levels), the characteristics in which each component of a product may be seen (Orme, 2006).

The conjoint analysis in this study is used to reveal the relative importance of certain hazards or deviations (levels) in 6 different periods (attributes) of the rearing process (product). Each period marks a different physiological stage in the development of the calf in becoming a lactating heifer (Brand et al., 1996). These 6 periods were (I) colostrum period until transition to milk, (II) milk period until weaning, (III) weaning until insemination, (IV) pregnancy period until 4 wk before calving, (V) 4 wk before calving until calving, and (VI) heifer in first lactation. The specific hazards for each rearing period were selected from both peer reviewed literature and based on assessment of the young stock rearing process by experienced dairy veterinarians. From the 59 specific hazards in the young stock rearing period, 56 have been described in the literature. The remaining 3 hazards were possible deviations indicated 
by experienced veterinarians, but could not yet be found as hazard in the literature (indicated in Table 1). Table 1 shows the attributes and levels of this ACA questionnaire; the ranking of hazards within each period is presented in the results.

The ACA questionnaire (Sawtooth Software Inc., 2005) consisted of 2 parts: a general section on background information of farmers or veterinarians and the actual ACA questions to rank the most common hazards perceived in the young stock rearing period. The ACA questionnaire part was divided into 4 sections with different types of questions to refine the US per measure or method of assessment. The first $3 \mathrm{sec}-$ tions were preference questions on the same hazards in various formats; the actual ranking of the hazards occurred in the fourth section. In the current study, a respondent's US is a measurement of his or her relative strength of preference for a given hazard in 1 of the 6 periods of the rearing process. The absolute values of the utilities have no inherent meaning. The US itself reflects a score of a hazard relative to the others and was used to rank the various hazards.

\section{Data Collection and Analysis}

After 8 wk on the Internet, the ACA questionnaire was closed and the data downloaded. In the program SSI Web (Sawtooth Software Inc., Sequim, WA), also used for writing both questionnaires, the US (preferences) of each respondent were extracted. As part 2 of the ACA questionnaire was the same for both veterinarians and farmers, the 2 groups could be compared with regard to their hazard perception.

\section{Consistency and Ranking of Hazards}

The consistency between the answers of the respondents was examined (called the correlation coefficient in the ACA program), by calculating the correlation between the US calculated over the first 3 sections of

Table 1. Ranking hazards in rearing periods I, II, and III based on median utility scores (US) for veterinarians $(\mathrm{V})$ and farmers (F)

\begin{tabular}{|c|c|c|c|c|}
\hline \multirow[b]{2}{*}{ Item $^{1}$} & \multicolumn{2}{|c|}{$\mathrm{US}^{2}$} & \multicolumn{2}{|c|}{ Ranking } \\
\hline & $\mathrm{V}$ & $\mathrm{F}$ & $\mathrm{V}$ & $\mathrm{F}$ \\
\hline \multicolumn{5}{|l|}{ I. Colostrum period until transition to milk } \\
\hline Diarrhea in newborn calf & $18.2^{*}$ & 12.2 & 1 & 2 \\
\hline Birth problems and stillbirth & 16.9 & 14.7 & 2 & 1 \\
\hline Insufficient feed intake & $16.2^{*}$ & 8.4 & 3 & 4 \\
\hline Paratuberculosis (Johne's disease) & $14.5^{*}$ & 7.8 & 4 & 5 \\
\hline Aberrant umbilical cord & 11.6 & 7.5 & 5 & 6 \\
\hline Malformations at birth & 10.5 & 8.0 & 6 & 5 \\
\hline Pneumonia caused by fetal distress & 10.4 & 6.0 & 7 & 8 \\
\hline Wrong animal identification ${ }^{3}$ & 3.7 & 9.5 & 8 & 3 \\
\hline Calf gets physically hurt ${ }^{3}$ (dung remover, pen, and so on) & 2.8 & 7.5 & 9 & 7 \\
\hline \multicolumn{5}{|l|}{ II. Milk period until weaning } \\
\hline Diarrhea in older calf & 13.2 & 10.1 & 1 & 5 \\
\hline Poor-growth-rate calves & 13.2 & 14.1 & 2 & 1 \\
\hline Wrong teat removal & 13.1 & 13.5 & 3 & 3 \\
\hline Paratuberculosis (Johne's disease) & 10.8 & 11.2 & 4 & 4 \\
\hline Pneumonia & 10.0 & 13.7 & 5 & 2 \\
\hline Aberrant umbilical cord & 5.7 & 7.4 & 6 & 6 \\
\hline Overcrowding & 3.8 & 4.7 & 7 & 7 \\
\hline Pain during or after dehorning & 2.0 & 4.1 & 8 & 8 \\
\hline \multicolumn{5}{|l|}{ III. Weaning until insemination } \\
\hline Over condition & $13.7^{*}$ & 9.9 & 1 & 5 \\
\hline Worm infection & 13.2 & 14.4 & 2 & 1 \\
\hline Lungworm infection & 12.7 & 13.5 & 3 & 3 \\
\hline Diarrhea after weaning & 12.0 & 9.8 & 4 & 7 \\
\hline Transfer of diseases from neighboring cattle & 10.5 & 10.4 & 5 & 4 \\
\hline Paratuberculosis (Johne's disease) & 9.5 & 9.9 & 6 & 6 \\
\hline Fasciola hepatica infection & 9.0 & 9.1 & 7 & 8 \\
\hline Lameness & 6.3 & $14.3^{*}$ & 8 & 2 \\
\hline Older calf not pregnant before 15 mo old ${ }^{3}$ & 5.1 & 4.6 & 9 & 9 \\
\hline Trichophyton verricosum infection & 0.2 & $2.6^{*}$ & 10 & 10 \\
\hline
\end{tabular}

${ }^{1}$ Hazards named in bold indicate the 3 most relevant hazards in each rearing period.

${ }^{2}$ Utility scores of the veterinarians are used as the reference category.

${ }^{3}$ Hazards not defined as such in literature.

${ }^{*} P<0.05$. 
Table 2. Ranking hazards in rearing periods IV, V, and VI based on median utility scores (US) for veterinarians $(\mathrm{V})$ and farmers $(\mathrm{F})$

\begin{tabular}{|c|c|c|c|c|}
\hline \multirow[b]{2}{*}{ Item $^{1}$} & \multicolumn{2}{|c|}{$\mathrm{US}^{2}$} & \multicolumn{2}{|c|}{ Ranking } \\
\hline & $\mathrm{V}$ & $\mathrm{F}$ & $\mathrm{V}$ & $\mathrm{F}$ \\
\hline \multicolumn{5}{|l|}{ IV. Pregnancy period until $4 \mathrm{wk}$ before calving } \\
\hline Mastitis & 16.7 & 17.7 & 1 & 1 \\
\hline Abortion & 15.5 & 15.2 & 2 & 2 \\
\hline Poor-growth-rate pregnant heifers & 12.6 & 14.1 & 3 & 3 \\
\hline Lungworm infection & 11.5 & 10.1 & 4 & 6 \\
\hline Over condition & 9.7 & 9.7 & 5 & 7 \\
\hline Worm infection or sudden weight loss & 9.5 & 12.0 & 6 & 5 \\
\hline Overcrowding & 8.5 & 7.1 & 7 & 8 \\
\hline Lameness & 8.4 & $13.4^{*}$ & 8 & 4 \\
\hline Fasciola hepatica infection & 1.8 & 6.2 & 9 & 9 \\
\hline Trichophyton verricosum infection & 0.4 & 0.9 & 10 & 10 \\
\hline \multicolumn{5}{|l|}{ V. 4 wk before calving until calving } \\
\hline Feed intake deviations & 16.2 & 14.3 & 1 & 2 \\
\hline Mastitis & 15.9 & 17.3 & 2 & 1 \\
\hline Abomasal displacement & 14.1 & 12.5 & 3 & 3 \\
\hline Overcrowding & 10.3 & 3.7 & 4 & 11 \\
\hline Heifer has difficulties with calving & 10.3 & 10.6 & 5 & 5 \\
\hline Worm infection or sudden weight loss & 10.2 & 10.2 & 6 & 6 \\
\hline Lungworm infection & 9.5 & 7.0 & 7 & 7 \\
\hline Lameness & 7.4 & $12.1^{*}$ & 8 & 4 \\
\hline Udder edema & 7.2 & 5.7 & 9 & 8 \\
\hline Milk fever in heifers & 3.6 & 5.1 & 10 & 10 \\
\hline Fasciola hepatica infection & 2.4 & 5.3 & 11 & 9 \\
\hline \multicolumn{5}{|l|}{ VI. Heifer in first lactation } \\
\hline Mastitis & 15.9 & 15.9 & 1 & 1 \\
\hline Feed intake deviations & 14.7 & 13.6 & 2 & 3 \\
\hline Retained placenta & 14.5 & 11.9 & 3 & 4 \\
\hline Long-lasting milk fever & $13.4^{*}$ & 9.8 & 4 & 6 \\
\hline Lameness & 12.4 & 11.2 & 5 & 5 \\
\hline Abomasal displacement & 11.5 & 8.5 & 6 & 7 \\
\hline Heifers with wrong udders or teats & 7.5 & $14.8^{*}$ & 7 & 2 \\
\hline Udder edema & 7.1 & 4.8 & 8 & 10 \\
\hline Lungworm infection & 6.6 & 5.3 & 9 & 8 \\
\hline Worm infection or suddenly losing weight & 5.8 & 5.1 & 10 & 9 \\
\hline Fasciola hepatica infection & 2.0 & 2.9 & 11 & 11 \\
\hline
\end{tabular}

${ }^{1}$ Hazards named in bold indicate the 3 most relevant hazards in each rearing period.

${ }^{2}$ Utility scores of the veterinarians are used as the reference category.

$* P<0.05$.

the questionnaire and the actual ranking scores during the final section of the questionnaire. At the end of each questionnaire, the respondents could give their comments and were asked to list their e-mail address, so as to provide them with the results. For more detailed information about the concept and principles of ACA and the correlation coefficient, we refer to the ACA User Manual 5.2 (Sawtooth Software Inc., 2005; see also, Johnson, 1989, 1991; Green and Srinivasan, 1990; Green et al., 1991).

As the US were not normally distributed, medians, instead of means, per individual hazard were calculated to interpret them. All hazards were ranked within each of the 6 periods separately for the farmer and veterinarian groups (Tables 1 and 2).

To evaluate the consistency in the answers of the respondents, literature suggests using the correlation cutoff value of $30 \%$ to include or exclude participants from the final analysis (van Schaik et al., 1998; Valeeva et al., 2005). Whether the correlation of $30 \%$ would be a correct cutoff value for the correlation coefficient in both "FARM" and "VET" was assessed by comparing the rankings of the US from respondents with 30 and $50 \%$ correlation (van Schaik et al., 1998).

\section{Hazard Perception}

Comparison of differences in hazard perception of farmers and veterinarians could only be done for different hazards within 1 period because the numbers of levels (hazards) per period (attribute) differ for each period. After ranking the hazards, the researchers also tested whether the height of the median US per hazard differed between veterinarians and dairy farmers within 
each 1 of the 6 periods using a Mann Whitney U-test. Statistical analysis was performed using SPSS (PASW 18, Chicago, IL).

\section{RESULTS}

\section{Participants}

In total, 110 farmers and 26 veterinarians participated in the survey. Due to the chosen cutoff value (correlation $>30 \%$ ), 30 of the 110 farmers and 9 of the 26 veterinarians were excluded from the final US calculations.

The remaining 97 respondents (both farmers and veterinarians) needed an average of $31 \mathrm{~min}$ to complete the internet ACA questionnaire (range $=11-115 \mathrm{~min}$ ). The average consistency in answering of all farmers and veterinary respondents was 67.1 and $63.0 \%$ with a standard deviation of 19.4 and $20.4 \%$, respectively.

\section{General Questions Questionnaire}

Farmers. Over $70 \%$ of the participating farmers reared between 15 and 45 replacement heifers per year on average. More than $75 \%$ of the farmers had a goal in their young stock rearing program, although not in a written format. Almost $20 \%$ of farmers stated they did not have a vision or clear target for their heifer-rearing process. On most farms $(72 \%)$, the farmer is the person responsible for the replacement animals.

Veterinarians. More than $95 \%$ of the respondents had over $3 \mathrm{yr}$ of experience in the dairy industry and serviced 50 dairy farms or more each. Over $90 \%$ of the respondents collaborated with at least 3 specialist dairy veterinarians in their practice. No veterinarians had over $50 \%$ of their dairy farms in an HHPM program, whereas $43 \%$ had less than $10 \%$ of their dairy farms in such a program.

More than $65 \%$ of the veterinarians gave advice regarding young stock rearing, whenever deemed necessary, without the farmer asking for advice. Most of the time (63\%) the advice is given in a written format and includes a follow-up visit, but in $30 \%$ of the cases advice is given (verbally) without documentation and follow-up. Structural advice by veterinarians, including preset protocols without conducting any clinical curative work, was provided by less than $10 \%$ of the veterinarians.

\section{Management Decisions: Farmers Versus Veterinarians}

To evaluate the differences in perception of some management decisions during the young stock rearing process, 3 questions were asked to both farmers and veterinarians. Farmers were asked the following questions: (1) "When does selection of animals take place in the young stock rearing?"; (2) "On which criteria is this selection based?"; and (3) "What determines whether a heifer is to be inseminated?" Veterinarians were asked what they believed the answers from farmers would be for all 3 questions. The main selection moment is directly after birth (farmers $=62.7 \%$ ) and the selection of replacement animals is mainly based on pedigree (farmers $=80.1 \%$ ), whereas the age of heifer mainly determines the time of insemination (farmers $=73.6 \%$ ), followed by weight at insemination (farmers $=50.9 \%$ ). Significant differences were found for the first question, as $7.3 \%$ of farmers chose "Selection within the first 8 to 10 wk after birth" versus just $22.2 \%$ of veterinarians $(P$ $=0.022$ ), and $10.0 \%$ of farmers chose "Selection within 100 days after birth" versus $29.6 \%$ of veterinarians $(P=$ 0.008). Likewise, significant differences were found for the third question, as $4.5 \%$ of farmers chose "Selection is based on the number of inseminations of an animal" compared with $22.2 \%$ of veterinarians $(P=0.002)$.

\section{Adaptive Conjoint Analysis}

Hazard Perception and Questionnaire. In period I (colostrum period until transition to milk), "Diarrhea in newborn calf," "Birth problems and stillbirth," and "Insufficient feed intake" were the 3 most important hazards according to veterinarians. Farmers confirmed the first 2 but ranked "Wrong animal identification" as the third most important hazard. The median US for the hazards "Diarrhea in newborn calf," "Insufficient feed intake," and "Johne's disease" were significantly higher and considered as more important by veterinarians $(P=0.010,0.003$, and 0.013 , respectively; Table $1)$.

The most important differences in hazard ranking in period II (milk period until weaning) were that veterinarians ranked "Pneumonia" lower than farmers did (rank 2 vs. 5) and indicated that "Diarrhea in older calves" was more important (rank 5 vs. 2). Important hazards for both groups were "Poor growth rate in calves" and "Wrong extra teat removal."

For period III (weaning until insemination), "Overcondition" was a significantly more important hazard for veterinarians in both ranking and absolute value $(P$ $=0.013$ ), whereas "Lameness" was, again, significantly more important to farmers in ranking and absolute value (rank 8 vs. $2 ; P=0.001$ ). The same period also showed that "Diarrhea after weaning" is ranked higher by veterinarians (rank 4 vs. 7) compared with farmers. Important hazards for both groups were "Lungworm infection" and "Worm infection or sudden weight loss." 
In period IV (pregnancy period until 4 wk antepartum) the hazard "Lameness," just outside the top 3 of the farmers, was found to rank higher and also be a significantly more important hazard within the farmer group compared with veterinarians (rank 13 vs. $8 ; P=$ 0.002). Important hazards for both groups were "Mastitis," "Abortion," and "Poor growth rate in heifers" (Table 2).

When veterinarians and farmers are compared for their scores in period $\mathrm{V}$ ( $4 \mathrm{wk}$ before calving until calving) the most remarkable differences in ranking and absolute US were the rankings of "Overcrowding" and "Lameness," the former significantly more important to veterinarians (rank 4 vs. $11 ; P=0.037$ ) and the latter significantly more important to farmers (rank 8 vs. 4; $P=0.016$ ). Important hazards for both groups were "Feed intake deviations," "Mastitis," and "Abomasal displacement" (Table 2).

Finally, in period VI (heifer in first lactation), the ranking and absolute US for "heifers with wrong udder or teats" were significantly higher for farmers than for veterinarians (rank 7 vs. $2 ; P=0.011$ ), whereas veterinarians had a slightly higher US for the hazards "Edema" (rank 8 vs. 10) and "Long-lasting milk fever" (rank 4 vs. $6 ; P=0.012$ ). Important hazards for both groups were "Mastitis," "Feed intake deviations," and "Retained placenta" (Table 2).

At the end of each ACA questionnaire it was possible to make remarks and indicate whether (important) hazards had been lacking. The most frequent remarks were: "It was a difficult questionnaire to complete," "It took me a long time to complete the questionnaire," "Some combinations of hazards are not very common," and "The questions where I had to compare different groups of hazards were very hard to answer, I had difficulties selecting one combination." The most common remark on the contents was "Fasciola hepatica infections are not common in Holland." No respondents remarked that (important) hazards had been missed.

Consistency Cutoff Values. When only respondents answering at a consistency of $50 \%$ were taken into account, no differences in hazard ranking lists for each period were found between veterinarians and farmers (data not shown). This indicates that $30 \%$ can be used as cutoff value for both ACA questionnaires, resulting in a higher total number of respondents useful for both ACA questionnaires.

\section{DISCUSSION}

The number of respondents left ("VET" $\mathrm{n}=17$; "FARM" $\mathrm{n}=80$ ) after applying the cutoff value is above average compared with other animal science studies that used the ACA technique, and included expert numbers varying between 5 and 52 (van Schaik et al., 1998; Fels-Klerx et al., 2000; Haslam and Kestin, 2003; Angus et al., 2005; Lievaart and Noordhuizen, 2011). A known problem in surveys, such as the ACA, is selection bias; accordingly, this applies to our study, as the selection of veterinarians was based on the criteria of offering a herd health service to their clients, which could possibly be a subpopulation of all ruminant veterinarians in the Netherlands. The definition of a herd health service is also debatable; frequency and content are discussed in other studies (Lievaart and Noordhuizen, 1999; Lievaart et al., 1999), but the number of practices offering this service in the Netherlands was around $90 \%$ in the 1990s (Lievaart and Noordhuizen, 1999; Lievaart et al., 1999) and has risen to $100 \%$, as it is now a requirement by the Dutch Government for dairy farmers. Each dairy farmer signs a contract with a veterinarian responsible for the use of antibiotics on his farm (prescription and delivery), but also plans a specific animal health plan for his or her farm. The farmers that responded to this survey are likely to be biased toward more proactive farmers, those who are keen to share and gather knowledge in any possible way; however, we believe these farmers are also capable to provide an informed decision on hazards regarding young stock rearing. A possible disadvantage of the approach used in our survey (clinical perception rather than quantitative epidemiology) is that respondents base their perception on different levels of experience and knowledge. Besides bias, confounding factors in the respondents, especially farmers, could affect the results. Although, dairy farms in the Netherlands are all quite similar, with a small range in number of animals, types of housing, number of people working on the farm (predominantly family farms), and climate.

The average time a respondent needed to complete the questionnaire was $31 \mathrm{~min}$, matching the a priori estimated time of $30 \mathrm{~min}$. Still, the remarks about the difficulty of the questionnaire are to be taken seriously because the respondents' difficulties could hamper proper answering or motivation to cooperate. The large amount of levels (59 in total) combined with the 20 pair-wise comparison questions might have been perceived as time-consuming and hard to complete. Reducing the number of levels (hazards) was considered, but we deducted it would lead to a less complete view of hazard perception of the whole young stock-rearing process. The consistency in answering was 67.1 and $63.0 \%$ on average for farmers and veterinarians, respectively, well beyond the respondent inclusion criterion of $30 \%$ consistency in answering recommended in the literature (van Schaik et al., 1998; Valeeva et al., 2005).

Hazards, such as an infectious bovine rhinotracheitis, bovine viral diarrhea, or Salmonella infection, were not 
selected as attributes in this survey. These diseases are of major importance for animal health on dairy farms, but they do not represent typical hazards in the young stock-rearing process.

In the introduction of each ACA questionnaire, at each part of the questionnaire, and in the formulation of each question, it was made clear that respondents should give (groups of) hazards most threatening to animals the highest scores (greatest threat or danger). As the preferences of farmers are based on experiences and knowledge on the farm and the preferences of veterinarians are based on experiences in the field, in practice, and in training, both their median US include the probability a hazard will occur as well as the impact of that single hazard. In formal risk analysis, risk (R) can be defined as the outcome of the interaction between probability $(\mathrm{P})$ and impact $(\mathrm{I})$, calculated as $\mathrm{R}=\mathrm{P} \times$ I (Noordhuizen et al., 2008a).

The US in the ACA questionnaire are comparable to the outcome of $\mathrm{P} \times \mathrm{I}$, indicating that hazards are more or less important compared with others. Still, formal quantitative epidemiological research is needed to draw more exact conclusions about the incidence (probability) or the effects (impact) of hazards. Conversely, when US are the same for farmer and veterinarians (e.g., period IV), perception of the probability and impact of hazards might still differ due to farm- or region-specific differences.

Paratuberculosis (Johne's disease) is outside the top 3 most important hazards in both period I and II, but, in both periods, it is very important to both farmers and veterinarians (i.e., in their top 5). The importance of this hazard diminishes in period III together with the susceptibility of animals being infected with Johne's disease.

For some hazards, the differences in ranking as well as the differences in preference was significant between farmers and veterinarians. For example, "Diarrhea in newborn" in period I (most important for veterinarians, 2nd most important for farmers), "Lameness" in different periods (high-ranking for farmers, low-ranking for vets), and "Over-conditioning" of animals in the period III (low-ranking for farmers, high-ranking for vets). However, it is well known that diarrhea in newborn calves, lameness, and over-conditioning can lead to unfavorable situations for both animal health and welfare and growth and development in the young stock rearing period or in adult dairy cows. (Robison et al., 1988; Sejrsen et al., 2000; Leach et al., 2005). The differences in hazard perception and the significant differences in the perception regarding some management decisions indicate that farmers and veterinarians differ in their opinions and insights in farm management. This finding underlines the importance of communication in the further development of veterinary advisory practice in preventive risk management programs (Cannas da Silva et al., 2006; Jansen et al., 2010).

The ultimate goal of risk management programs in veterinary advisory practice (HHPM or HACCP) is to identify what should change to avoid or prevent deviations to improve farm results (Brand et al., 1996; Noordhuizen and Boersema, 2008; Noordhuizen et al., 2008a). But, as described in the introduction, for several reasons, veterinarians struggle with the marketing of monitoring and control programs regarding young stock to farmers. We found that hazard perception differs between farmers and veterinarians for this period. However, more important is why the farmers' hazard perception differs in the first place. This insight in (hazard) awareness of the farmer is the first step in one of the most accepted marketing models, the attention, interest, desire, action model. Our results underline that communication with the farmers and marketing knowledge of the veterinarian are key elements in the acceptance of risk management programs by farmers (Cannas da Silva et al., 2006; Noordhuizen et al., 2008b).

The 3 or 5 most important hazards from each rearing period (for different periods sometimes the same hazards) can be used for designing tailor-made HHPM programs with a specific focus on young stock rearing. Before this can be done, however, a further analysis of the most relevant risk factors associated with each defined hazard should take place.

The outcomes of this study can be used to develop a HACCP-like QRM program regarding young stock rearing. These programs have a more preventive character than HHPM programs because screening regarding risk factors and the prediction of when and what kind of hazards will occur on a specific farm (risk-profile) is involved. Based on the outcomes of this study, we learned that hazard perception of veterinarians and farmers differs, and that the success of future QRM programs is based on the ability of the veterinarian (advisor or auditor) to approach and communicate with farmers in the right way concerning preventive medicine and risk management.

\section{ACKNOWLEDGMENTS}

The authors acknowledge all participating respondents for the time and effort put into this adaptive conjoint questionnaire study. Special thanks to the Information and Communication Technology team of the Veterinary Faculty Utrecht, Utrecht, the Netherlands (Aart de Groot), for providing the knowledge and help at transferring the adaptive conjoint questionnaires to the World Wide Web. 


\section{REFERENCES}

Angus, L. J., H. Bowen, L. A. S. Gill, T. G. Knowles, and A. Butterworth. 2005. The use of conjoint analysis to determine the importance of factors that affect on-farm welfare of the dairy cow. Anim. Welf. 14:203-213.

Bell, M. J., E. Wall, G. Russell, D. J. Roberts, and G. Simm. 2010. Risk factors for culling in Holstein-Friesian dairy cows. Vet. Rec. $167: 238-240$

Boersema, J., J. Noordhuizen, A. Vieira, J. Lievaart, and W. Baumgartner. 2008. Imbedding HACCP principles in dairy herd health and production management: Case report on calf rearing. Ir. Vet. J. 61:594-602.

Brand, A., J. P. T. M. Noordhuizen, and Y. H. Schukken. 1996. Herd Health and Production Management in Dairy Practice. Wageningen Pers, Wageningen, the Netherlands.

Cady, R. A., and T. R. Smith. 1996. Economics of heifer raising programs Pages 7-24 in Proc. Calves, Heifers, and Dairy Profitability National Conference, Harrisburg, PA.

Cannas da Silva, J., J. P. Noordhuizen, M. Vagneur, R. Bexiga, C. C. Gelfert, and W. Baumgartner. 2006. Veterinary dairy herd health management in Europe: Constraints and perspectives. Vet. Q. $28: 23-32$

CRV. 2009. CRV Jaarstatistieken Nederland (in Dutch). CRV Holding BV, Arnhem, the Netherlands. http://www.crv4all.nl/downloads/ jaarverslagen/crv-jaarstatistieken-2009.pdf.

Derks, M., L. M. van de Ven, T. van Werven, W. D. Kremer, and H. Hogeveen. 2012. The perception of veterinary herd health management by Dutch dairy farmers and its current status in the Netherlands: A survey. Prev. Vet. Med. 104:207-215.

Evans, J. R., and W. M. Lindsay. 1996. The Management and Control of Quality. West Publishing Co., St. Paul, MN.

FAO (Food and Agriculture Organization of the United Nations). 1997. Hazard analysis critical control points (HACCP) system and guidelines for its application. FAO, Rome, Italy.

Fels-Klerx, H. J., H. S. Van der Horst, and A. A. Dijkhuizen. 2000. Risk factors for bovine respiratory disease in dairy youngstock in the Netherlands: The perception of experts. Livest. Prod. Sci. $66: 35-46$

Green, P. E., K. Abba, and K. A. Manoj. 1991. Adaptive conjoint analysis: Some caveats and suggestions. J. Mark. Res. 23:215-222.

Green, P. E., and V. Srinivasan. 1990. Conjoint analysis in marketing: New developments with implications for research and practice. J Mark. Res. 54:3-19.

Hadley, G. L., C. A. Wolf, and S. B. Harsh. 2006. Dairy cattle culling patterns, explanations, and implications. J. Dairy Sci. 89:22862296.

Haslam, S. M., and S. C. Kestin. 2003. Use of conjoint analysis to weight assessment measures for boiler chickens in UK husbandry systems. Anim. Welf. 12:669-675.

Jansen, J., C. D. Steuten, R. J. Renes, N. Aarts, and T. J. Lam. 2010. Debunking the myth of the hard-to-reach farmer: Effective communication on udder health. J. Dairy Sci. 93:1296-1306.

Johnson, R. 1989. Accuracy of utility estimation in ACA. Working Paper. Sawtooth Software, Sequim, WA

Johnson, R. 1991. Comment on adaptive conjoint analysis: Some caveats and suggestions. J. Mark. Res. 28:223-225.
Leach, K. A., J. E. Offer, I. Svoboda, and D. N. Logue. 2005. Effects of type of forage fed to dairy heifers: Associations between claw characteristics, clinical lameness, environment and behaviour. Vet. J. 169:427-436.

Lievaart, J., J. Noordhuizen, D. Buckley, and S. Van Winden. 2008. The marketing of herd health and production management services on Dutch dairy farms: Perceptions of dairy farmers and their veterinary surgeons. Ir. Vet. J. 61:668-676.

Lievaart, J. J., and J. P. Noordhuizen. 1999. Veterinary assistance to dairy farms in the Netherlands: An assessment of the situation by dairy farmers. Tijdschr. Diergeneeskd. 124:734-740.

Lievaart, J. J., and J. P. Noordhuizen. 2011. Ranking experts' preferences regarding measures and methods of assessment of welfare in dairy herds using adaptive conjoint analysis. J. Dairy Sci. 94:3420-3427.

Lievaart, J. J., J. P. Noordhuizen, N. den Daas, and H. Jorritsma. 1999. Veterinary supervision of dairy facilities in the Netherlands: What do veterinarians think about participating and non-participating cattle owners? Tijdschr. Diergeneeskd. 124:434-438.

Mohd Nor, N., W. Steeneveld, M. C. Mourits, and H. Hogeveen. 2012 Estimating the costs of rearing young dairy cattle in the Netherlands using a simulation model that accounts for uncertainty related to diseases. Prev. Vet. Med. 106:214-224.

Mourits, M. C., A. A. Dijkhuizen, R. B. Huirne, and D. T. Galligan. 1997. Technical and economic models to support heifer management decisions: Basic concepts. J. Dairy Sci. 80:1406-1415.

Noordhuizen, J., and S. J. Boersema. 2008. Applying HACCP-based quality risk management on dairy farms. Tijdschr. Diergeneeskd. 133:153

Noordhuizen, J., J. Cannas da Silva, S. J. Boersema, and A. Vieira. 2008a. Applying HACCP-based Quality Riks Management on dairy farms. Wageningen Academic Publishers, Wageningen, the Netherlands.

Noordhuizen, J. P., M. J. van Egmond, R. Jorritsma, H. Hogeveen, T. van Werven, P. L. Vos, and J. J. Lievaart. 2008b. Veterinary advice for entrepreneurial Dutch dairy farmers: From curative practice to coach-consultant: What needs to be changed? Tijdschr. Diergeneeskd. 133:4-8.

Orme, B. K. 2006. Getting Started with Conjoint Analysis; Strategies for Product Design and Pricing Research. Research Publishers LLC., Madison, WI.

Robison, J. D., G. H. Stott, and S. K. DeNise. 1988. Effects of passive immunity on growth and survival in the dairy heifer. J. Dairy Sci. 71:1283-1287.

Sawtooth Software Inc. 2005. ACA User Manual Version 5. Sawtooth Software Inc., Sequim, WA.

Sejrsen, K., S. Purup, M. Vestergaard, and J. Foldager. 2000. High body weight gain and reduced bovine mammary growth: Physiological basis and implications for milk yield potential. Domest. Anim. Endocrinol. 19:93-104.

Valeeva, N. I., M. P. Meuwissen, A. G. Lansink, and R. B. Huirne 2005. Improving food safety within the dairy chain: An application of conjoint analysis. J. Dairy Sci. 88:1601-1612.

van Schaik, G., A. A. Dijkhuizen, R. B. Huirne, and G. Benedictus. 1998. Adaptive conjoint analysis to determine perceived risk factors of farmers, veterinarians and AI technicians for introduction of BHV1 to dairy farms. Prev. Vet. Med. 37:101-112. 